\title{
Development and Evaluation of an Advanced Training Technology Course Within a Union-Based Industrial Emergency Response Training Program
}

\author{
Jennifer A. Fernandez, ms, ${ }^{1}$ Luis Vazquez, ${ }^{\text {MPH, }}{ }^{2}$ Judith A. Daltuva, MSw, MA, ${ }^{1}$ * \\ Thomas G. Robins, $\mathrm{MD}^{\mathrm{MPH}}{ }^{1}{ }^{1}$ and Melina Williams, $\mathrm{MPH}^{1}$
}

\begin{abstract}
Background The Health and Safety Department of the United Automobile Workers recently introduced the use of Advanced Training Technologies (ATTs) into a previously successful Industrial Emergency Response (IER) program. The new curriculum attempted to incorporate web-based technology, while preserving the historical emphasis on the use of peer trainers and the Small Group Activity Method (SGAM) to promote team problem solving and worker empowerment.

Methods The University of Michigan evaluated the program by administering a survey combining open- and closed-ended questions to trainees.

Results Of the 46 respondents, most rated the program very highly, found that the use of internet technology allowed faster access to current information, reported peer trainers as one of program aspects they liked best, and did not find working in groups of three per computer difficult.

Conclusions It is possible to enhance a workplace health and safety training program through the introduction of ATT without compromising participant-centered, group learning program philosophies. Am. J. Ind. Med. 43:429-435, $2003 . \quad$ ๑) 2003 Wiley-Liss, Inc.
\end{abstract}

KEY WORDS: advanced training technologies; web-based training; internet; small group activity method; peer trainers; industrial emergency response; union

\section{INTRODUCTION}

There is increasing interest in using computer-based training to meet occupational health and safety training needs. Industry magazines often tout the benefits of distance and web-based learning, benefits which include flexibility, efficient use of time, the ability to train at multiple sites on

\footnotetext{
1Department of Environmental Health Sciences, School of Public Health, University of Michigan, Ann Arbor, Michigan

${ }^{2}$ United Automobile Workers' International Health and Safety Department, Detroit, Michigan

Contract grant sponsor: NIEHS; Contract grant number: NIH 2U45-ES06180-09.

${ }^{*}$ Correspondence to: Judith A. Daltuva, M6234 SPH II, 109 Observatory Rd., Ann Arbor, MI 48109-2029.E-mail: jdal@umich.edu
}

Accepted 19 November 2002

DOI 10.1002/ajim.10193. Published online in Wiley InterScience

(www.interscience.wiley.com) off-shifts, the decrease in instructor fees and expenses, the decrease in trainee travel costs, and the increase in efficient record-keeping. In addition, these articles claim more participation in training and better retention of material by trainees [McGregor, 1996; Hubiak, 1998; Santoro, 1998; Mills, 1999]. However, there is little, if any peer-reviewed literature assessing these claims of benefits.

Methodologies under the general rubric of ATTs include: computer-based training curricula using CD-ROMs; access to web sites and/or training using information on the internet; and televised, often interactive broadcasts of lectures and fora. Benefits of applying ATTs in higher education courses, such as occupational and environmental health and medicine, and in continuing health education and distance learning have been reported [Bagnall, 1995; Agius and Bagnall, 1998; Parsons, 2000].

As it can be expected that the US Occupational Safety and Health Administration (OSHA) and similar regulatory agencies will increasingly need to address the use of ATT in 
relation to compliance with hazard communication and related standards, evaluation of these methods will become increasingly important [National Institute for Environmental Health Sciences-Occupational Safety and Health Administration, 2001]. The technology needs to add value to the methods already proven efficacious if it is to be recommended for more general integration. Furthermore, the introduction of these technologies to a previously successful program might have negative impacts if not properly developed, instituted, and assessed.

This article describes the development, piloting, and evaluation of an ATT program by the International Union of the United Automobile, Agricultural Implement, and Aerospace Workers (UAW), which occurred between September 1999 and August 2000. This program builds on two successful techniques used in other UAW training programs: peer trainers called Local Union Discussion Leaders (LUDLs) and the Small Group Activity Method (SGAM), a participatory adult education technique [Kurtz et al., 1997; Fernandez et al., 2000]. This work was supported by a supplemental grant from the US National Institute of Environmental Health Sciences (NIEHS).

The ATT curriculum seeks to train UAW members and managers at UAW-represented facilities to access and interpret on-line occupational and environmental health resources to critically assess industrial emergency response (IER) activities at their facilities. Specific aims include:

- creating a web site that provides access to a variety of databases and links to other relevant web sites,

- developing a computer-based curriculum to train workers and managers on how to use environmental, occupational safety, and health data,

- training current LUDLs on the ATT curriculum and providing opportunities for them to deliver this training, and

- evaluating: (a) how participatory training approaches can be utilized in concert with ATTs, and (b) the overall effectiveness of computer-based training.

The University of Michigan (UM) has been involved with program planning and evaluation of the UAW's NIEHS sponsored training programs for over a decade. We present the results of a UM program evaluation with a focus on trainee evaluations for the newly developed ATT program.

\section{MATERIALS AND METHODS}

\section{Program Background}

The ATT program built on the experience of UAW Health and Safety staff with internet resources such as RTK NET (later, www.rtk.net) to find data on chemicals being discharged or shipped out of facilities as hazardous wastes
[Vazquez, 1999]. Materials maintained on the OSHA web site, particularly the Facility Inspection and Citation databases, also proved useful. Data from RTK NET and OSHA were combined to generate facility reports and assess training needs. Management personnel, union members, and union leadership saw these data as factual and undeniable. As available, these data were incorporated into UAW trainings such as IER classes to help trainees better understand chemical usage and discharge in their own workplaces and allow them to better prepare for chemical emergencies.

Supported by a supplemental grant from NIEHS, the UAW created a public web site (www.uaw.org/hs/at/ index.html) to be used in the ATT training. This web site has links to search engines in web sites maintained by US Environmental Protection Agency (EPA), US Department of Labor, US Centers for Disease Control and Prevention, state, county and Non-governmental Organizations. The web site includes descriptions of each of the database links to assist users in choosing which database might be the most useful for a particular problem.

\section{Program Description}

Partners from the UAW Health and Safety, LUDLs, and UM began to integrate new technology with the SGAM to create the ATT curriculum. RTK NET and the UAW Public Relations Department provided technical assistance. The involvement of LUDLs in the curriculum development process helped ensure that the items selected would be of interest to rank and file union members and would be readily understandable by them.

The five class objectives of the ATT program are to provide trainees with the ability to

- assess their company's environmental record,

- assess their company's potential for hazardous chemical release,

- assess OSHA compliance data and health information,

- interpret OSHA compliance data and health information, and

- critique their company's risk management plan.

The ATT curriculum consists of a case study of a UAWrepresented facility, followed by research on trainees' own facilities. The case study guides trainees to web-based and hard copy sources of data in seeking answers to questions about:

- what types and quantities of hazardous chemicals the plant discharges;

- what spills have been reported;

- what OSHA inspections and citations have been issued;

- what less hazardous chemicals could be used as substitutes within the plant; and, 
- what other occupational health and environmental information sources are available, such as the National Library of Medicine, the Centers for Disease Control, National Institute for Occupational Safety and Health, New Jersey Department of Health Hazardous Substance Factsheets, among others.

During the ATT course, trainees are divided into groups of three per computer. One member is responsible for researching hard copy factsheets, a second member is responsible for researching on the internet, while the third person is responsible for recording answers and assisting the other group members. During this process, trainees discuss their findings and work together to answer the questions. Roles are rotated so that each member of the group has the opportunity to perform each task.

\section{Evaluation}

To evaluate the ATT program, UM developed a two-part survey. The first section, completed before the class begins, gathers background data on the trainees. The second section, completed at the end of the course, contains closed- and open-ended questions concerning course materials, organization, goals, and participants' impressions of the training. This survey was piloted in conjunction with the training and later used during the UAW's Annual Health and Safety Conference held from March 22-24, 2000 at the Walter and May Reuther UAW Family Education Center at Black Lake (hereafter referred to as Black Lake).

Interview data were coded and entered into SPSS for Windows statistical software (SPSS, Inc., Chicago, IL) and cleaned by checking logic sequences and ranges for individual questions. Frequencies and descriptive statistics were generated for each quantitative variable. Bivariate Pearson correlation coefficients were also computed. Categories for qualitative responses were constructed based on themes, concepts, or similar features.

\section{Pilot Program}

Thirteen trainees (eight workers representing two industrial sites, one member of the Ann Arbor Ecology Center, and four LUDLs) participated in the pilot of the ATT program, held at UM. Two additional LUDLs facilitated. During the pilot, the above-described protocol was followed.

Several evaluation activities occurred during the training, including observation of group members and administration of the two-part survey. The participants were also questioned as beta testers, i.e., knowledgeable users who could provide information regarding technical problems they encountered. At the pilot's conclusion, a "report back" was held in which participants shared answers to the exercises, discussed problems with the curriculum, and made suggestions on how to improve the pilot curriculum. The feedback gathered during the pilot was used to make changes to the curriculum and web site prior to the first official programs held at Black Lake.

\section{Black Lake}

The ATT program was offered twice as an elective at Black Lake. To accommodate high demand, LUDLs also offered informal evening sessions on ATT. Evaluation data were not collected at the informal sessions.

\section{RESULTS}

\section{Pilot Program}

At the pilot's start, some problems were evident: not all of the links on the web page were functioning and both written and oral instructions lacked clarity. With individualized assistance from the instructors, groups were able to complete their tasks. Most participants quickly grasped the structure of the web site and several were able to assist the facilitators in circumventing non-functioning links.

Participants reported that they liked the structure and interface of the web site and found the content to be satisfactory and technically appropriate. Suggestions on how to improve the web site included introducing pull down menus, adding descriptions of the sites included in each link, clarifying instructions, and incorporating a tutorial.

Participants were also concerned about working in groups of three with each group having access to only one computer, even though more computers were available at the site. After an explanation of the theory behind SGAM, participants agreed that working in groups of three was effective but suggested that the groups should not be any larger.

Twelve of the thirteen participants completed evaluative questionnaires. In view of the small sample size, formal statistics were not computed. Nine of the twelve participants completing evaluation instruments reported at least some previous experience with the internet. Eleven trainees disagreed or strongly disagreed that working in a group was difficult. Trainees said the advantages of using the internet were the abundance of resources and the speed with which they could access information. The greatest difficulty with the program reported by most trainees was the disparate internet experience of trainees. Most trainees said that the training was relevant to their workplaces and communities and agreed that they would use the material in the future. Overall, the program was rated highly.

\section{Black Lake}

A total of 46 evaluations were collected from the 48 attendees at the two daytime sessions. Most of the 46 delegates were from Independent Parts and Suppliers 
(IPS) $(52.2 \%)$ and big three Automakers (Ford, General Motors, Daimler Chrysler) (32.6\%). Over half (53.3\%) were Health and Safety Committee members and all were union members. Males comprised $93.3 \%$ of the trainees attending the two sessions, and the average age of a trainee was 43.5 years.

All the delegates in the class reported previous computer use; $78.3 \%$ used e-mail and over $80 \%$ used the internet. The majority reported using the computer at home $(87 \%)$ or work (71.7\%). Most delegates reported spending 1-5 hr/week $(43.2 \%)$ or $6-10 \mathrm{hr} /$ week $(24.3 \%)$ on the internet. The remaining delegates reported spending less than $1 \mathrm{hr}(16.2 \%)$ or more than $10 \mathrm{hr}(16.2 \%)$ per week on the internet. The most commonly reported use of the internet was to find information (94.6\%). The majority of users said they were self-taught $(67.6 \%)$ and/or were taught by family and friends (45.9\%). A smaller percentage said they learned on the job $(29.7 \%)$ or in a class $(21.6 \%)$. These percentages total more than 100 as delegates were asked to check all that apply. Being classified as skilled trades was significantly correlated with having had an internet course $(\mathrm{r}=0.46)$. A substantial majority of all respondents (86.4\%) reported feeling somewhat or very comfortable using the internet.

Delegates' responses to an open-ended question regarding expectations for the class fell into two major categories. First, the majority wanted information, i.e., "to expand (their) knowledge of how to find more information related to Health and Safety." One delegate stated that he wanted to "find information on (his) neighborhood plant." The second major expectation was to learn how to use computers, the internet, and search engines.

As shown in Table I, the majority of delegates agreed that the instructions were easy to follow. However, a significant minority $(15.5 \%)$ either disagreed or strongly disagreed. Similar results were obtained regarding the fact sheets being helpful and the exercises being clearly written. The instructors were one of the program aspects delegates liked best. Almost all delegates agreed or strongly agreed (88.6\%) that the facilitators were available to answer questions. Approximately one quarter of delegates found working together at the computer difficult, while more than one half did not. When asked if everyone in their small group got a chance to look up information on the computer, $23.9 \%$ of delegates said no.

Although some delegates did not like having more than one person at a computer, many enjoyed "working together" and "learning from other people in the class." Delegates also liked the "relaxed atmosphere" and the "hands-on" features of the program, as well as the health and safety information received. Finally, $91.1 \%$ of delegates agreed or strongly agreed that they would use the material to locate information on their community or work site in the future.

The program aspects liked least were "unclear objectives" and the need for "more instruction before starting." Delegates also reported insufficient number of computers and inadequate equipment, for example, some laptop computers were used which made viewing of the screen from different angles difficult. Delegates also stated that they wanted more class time and a smaller class. People said that the room was "too crowded" and there were "too many people talking at once."

Respondents were asked to rate how much the ATT program would help them perform the five class objectives. For four out of the five categories listed, over $66 \%$ of the delegates responded with a rating of four or better on a fivepoint scale (Table II). Rating their ability to critique their company's risk management plan, $52.4 \%$ of delegates responded with a four or better (Table II).

Regarding course difficulty, $85.4 \%$ of the delegates responded that the course was just right, while $14.6 \%$

TABLE I. Distribution of Participant Responses to Questions Concerning Quality of the Health and Safety Environmental Resource Web Site Training Evaluation Questionnaire Given During the UAW Health and Safety Conference at Black Lake, 2000 (Data Are Combined for all Sessions: $\mathrm{n}=46$ )

\section{Please state how much you agree or disagree with the following statements:}

\begin{tabular}{|c|c|c|c|c|c|}
\hline & Strongly agree $(\%)$ & Agree (\%) & Neither agree nor disagree (\%) & Disagree (\%) & Strongly disagree (\%) \\
\hline 1a. The instructions were easy to follow & 11.1 & 44.4 & 28.9 & 11.1 & 4.4 \\
\hline $\begin{array}{l}\text { 1b. The fact sheets were helpful for completing } \\
\text { the exercises }\end{array}$ & 14.0 & 48.8 & 27.9 & 4.7 & 4.7 \\
\hline $\begin{array}{l}\text { 1c. The facilitators were available to answer } \\
\text { my questions }\end{array}$ & 29.5 & 59.1 & 6.8 & 4.5 & 0 \\
\hline 1d. The exercises were clearly written & 14.3 & 52.4 & 16.7 & 11.9 & 4.8 \\
\hline $\begin{array}{l}\text { 1e. It was difficult to work together as a group at } \\
\text { the computer }\end{array}$ & 31.1 & 26.7 & 15.6 & 20.0 & 6.7 \\
\hline $\begin{array}{l}\text { 1f. I will use the material presented in this class to } \\
\text { locate information on my community or work site } \\
\text { in the future }\end{array}$ & 40.0 & 51.1 & 4.4 & 2.2 & 2.2 \\
\hline
\end{tabular}


TABLE II. Distribution of Participant Responses to Questions on Expected Usefulness of the Health and Safety Environmental Resource Web Site Training Evaluation Questionnaire Given During the UAW Health and Safety Conference at Black Lake, 2000 (Data Are Combined for all Sessions: $n=46$ )

\begin{tabular}{|c|c|c|c|c|c|}
\hline & \multicolumn{4}{|c|}{ Notatall } & \multirow{2}{*}{$\begin{array}{c}\text { A lot } \\
5\end{array}$} \\
\hline & 1 & 2 & 3 & 4 & \\
\hline 3a. Assess your company's environmental record & 9.5 & 7.1 & 16.7 & 26.2 & 40.5 \\
\hline 3b. Assess your company's potential for hazardous chemical release & 9.5 & 7.1 & 14.3 & 33.3 & 35.7 \\
\hline 3c. Assess OSHA compliance data and health information & 9.3 & 2.3 & 20.9 & 18.9 & 48.8 \\
\hline 3d. Interpret OSHA compliance data and health information & 7.0 & 4.7 & 16.3 & 34.9 & 37.2 \\
\hline 3e. Critique your company's risk management plan & 9.5 & 7.1 & 31.0 & 26.2 & 26.2 \\
\hline
\end{tabular}

responded it was too difficult. Most (92.8\%) reported that the class was very or somewhat relevant to their workplace. The class was rated good or excellent by $77.7 \%$ of respondents. The course rating was significantly positively correlated with the average number of hours spent on the internet $(r=0.40)$. Additionally, delegates who reported that they would use the material were more likely to use e-mail $(r=0.42)$ and the internet $(r=0.42)$.

Faster access to a large volume of up-to-date information was reported as an advantage of using the internet for this training. As one delegate stated, "everything is right at your fingers." Delegates also thought the hands-on aspect of this training benefited novice computer users.

The area for improvement cited most often was investment in more and better equipment, such as improved keyboards and faster connections. To improve program instruction, one delegate suggested a "step-by-step program, with the leader showing the steps on an overhead projector."

\section{DISCUSSION}

An initial concern about the ATT program was whether the target population would embrace a technology-based class; however, the ATT sessions were one of the most popular electives at Black Lake. This high demand for computer-based learning was further demonstrated when delegates attended the informal evening sessions during their recreation time.

It is uncertain how representative class attendees were of rank-and-file union members. The delegates attending Black Lake tend to be union officials or health and safety representatives who perhaps have increased familiarity with computers. In addition, trainees self-selected the elective courses so those more comfortable with computers may have chosen ATT sessions. Indeed, all ATT trainees reported previous computer use. For some audiences, greater emphasis on basic computer skills may be required.
The UAW's approach to training seeks to build an interactive problem-solving team, where the interaction is worker to worker. Computers are designed primarily for use by one individual at a time, and by their very nature tend to isolate individuals; individuals tend to interact with the computer instead of team members. The ATT program was designed to avoid these potentially negative attributes of working with computers. The ATT program requires trainees to work in groups of three that work to complete tasks jointly,thus promoting a problem-solving team. It has been posited that such an approach is critical to have training programs successfully address workplace environmental hazards [National Institute for Environmental Health Sciences, 1999]. Initially, some trainees expressed a preference for working alone at a computer. For this reason, at the beginning of each class trainers now explain the emphasis the training philosophy places on group interaction.

Success in using the SGAM for health and safety training has been documented [Luskin et al., 1992; McQuiston et al., 1994; Merrill, 1994; Kurtz et al., 1997; Fernandez et al., 2000]. Use of SGAM avoids the potential shortcomings inherent in computer-based training. Trainees reported that they liked working together on tasks and learning from each other. For example, the rotation of roles specified in the ATT curriculum allows trainees who are more familiar with computers to assist those in their group who are not. This trainee-to-trainee assistance was confirmed by observations of UM evaluators and UAW staff.

One of the strengths of the current program as reported by trainees was the use of LUDLs as trainers who were available to address questions. It is also worth noting that the use of LUDLs as trainers ensures that the ATT class complies with the intent of OSHA standards, which require that trainees have the opportunity to ask questions [Occupational Safety and Health Administration, 1994a,b, 1997, 1999]. As peers of the trainees, LUDLs were able to create a relaxed classroom atmosphere that trainees reported as an important program strength. Furthermore, 
seeing their peers successfully utilizing technology may contribute to the trainees' own confidence in working with technology.

\section{IMPLICATIONS FOR FUTURE PRACTICE}

Transporting the ATT program to Black Lake posed several challenges. Specialized skills, such as knowledge of modems and transfer rates, are required to arrange a training room with half a dozen computers connected to the internet. Future programs should include a technical support person who could help overcome problems during set-up in the field. This person could also assist trainers in becoming familiar with the technical aspects of computers to increase their comfort with presenting the course.

Effective equipment appears vital to the successful incorporation of SGAM with technology as it will help overcome problems encountered during set-up and will increase trainee satisfaction. Although more difficult to transport than laptops, desktop monitors were more easily viewed by groups of three. The newer, large, but relatively low weight, flat screens may be an attractive solution.

The ATT program was developed as a stand-alone 3-hr training program. Based on the success of the program, the UAW plans to integrate the ATT curriculum with other training programs, such as the 24-hr IER training and the 8-hr IER refresher.

\section{CONCLUSION}

Worker empowerment is a cornerstone of all UAW health and safety training. The UAW strives to create selfsufficient trainees who work together to accomplish goals. When planning the ATT program it was important to ensure worker participation, because if participation decreases, empowerment will also [National Institute for Environmental Health Sciences, 1999]. As the quantitative and qualitative data indicate, the current program successfully integrated peer trainers and SGAM with ATTs. This combination of methods appears fully consistent with the UAW's overall training philosophy.

\section{ACKNOWLEDGMENTS}

The authors wish to thank LUDLs, Kim Lane, UAW Local 600, and Donna Swartwood, UAW Local 3000, for their help in facilitating and developing the program. We also thank the staff from the United Automobile Workers' International Health and Safety Department, particularly Andy Comai, for his help in devising the case study and developing the program. In addition, we express our appreciation for the consulting and technical assistance offered by RTK NET during the pilot program. We are grateful to Anne Heybey for her competent work in preparing this article. This study was funded by a grant from the National Institute of Environmental Health Sciences to the United Automobile Workers' International Health and Safety Department.

\section{REFERENCES}

Agius RM, Bagnall G. 1998. Development and evaluation of the use of the Internet as an educational tool in occupational and environmental health and medicine. Occup Med 48:337-343.

Bagnall G. 1995. Postgraduate training in health education/promotion: The demand from potential students for distance learning. Health Educ J 54:163-175.

Fernandez JA, Daltuva JA, Robins TG. 2000. Industrial emergency response training: An assessment of long-term impact of a union-based program. Am J Ind Med 38:598-605.

Hubiak S. 1998. Click on to effective training. Safety and Health 158: 116-118.

Kurtz JR, Robins TG, Schork MA. 1997. An evaluation of peer and professional trainers in a union-based occupational health and safety training program. J Occup Environ Med 39:661-671.

Luskin J, Somers C, Wooding J, Levenstein C. 1992. Teaching health and safety: Problems and possibilities for learner-centered training. Am J Ind Med 22:665-676.

McGregor EG. 1996. Can software manufacturers bridge the vision gap? Occup Health Saf 65:72, 74, 76.

McQuiston TH, Coleman P, Walerstein NB, Marcus AC, Morawetz JS, Ortlieb DW. 1994. Hazardous waste worker education: Long term effects. J Occup Med 36:1310-1323.

Merrill M. 1994. Trust in training: The oil, chemical, and atomic workers international union worker-to-worker training program. Occup Med State of the Art Reviews 9:341-354.

Mills L. 1999. HazCom training goes hi-tech. Safety and Health 159: $50-54$.

National Institute for Environmental Health Sciences. 1999. NIEHS Technical Workshop: Computer and internet-based learning methods for safety and health training. Bethesda, MD: National Institute for Environmental Health Sciences.

National Institute for Environmental Health Sciences-Occupational Safety and Health Administration. 2001. NIEHS/OSHA Joint Grantee Workshop: Best practices for worker training. Held in Chicago, April 17-19, 2001.

Occupational Safety and Health Administration. 1994a. The acceptability of a computer based, self-paced training program for use in meeting the refresher training requirements of the standard. OSHA Standards Interpretation and Compliance Letter, October 11, 1994. http://www.osha-slc.gov/OshDoc/Interp_data/I19941011B.html. Accessed on February 15, 2001.

Occupational Safety and Health Administration. 1994b. The use of computer-based training to satisfy OSHA training requirements. OSHA Standards Interpretation and Compliance Letter, November 22, 1994. http://www.osha-slc.gov/OshDoc/Interp_data/I19941122B.html. Accessed on February 15, 2001.

Occupational Safety and Health Administration. 1997. Appropriateness of computer-based interactive training programs to satisfy required OSHA training. OSHA Standards Interpretation and Compliance 
Letter, June 11, 1997. http://www.osha-slc.gov/OshDoc/Interp_data/ I19970611.html. Accessed on February 15, 2001.

Occupational Safety and Health Administration. 1999. Webbased HAZWOPER refresher training: Hands-on training an trainer accessibility. OSHA Standards Interpretation and Compliance Letter, October 20, 1999. http://www.osha-slc.gov/OshDoc/ Interp_data/I19991020B.html. Accessed on May 17, 2000.
Parsons J. 2000. Having trouble keeping up with your professional development needs? The Synergist, September:21-23.

Santoro JA. 1998. Going interactive. Occup Health Saf 67:144, 146148.

Vazquez L. 1999. RTK.net-A Resource for Workers. New Solut 9:349-358. 